\title{
Prognose, follow-up en behan- delkeuze bij kinderen met tubereuze sclerose en epilepsie
}

Patiënten en ouders van kinderen bij wie de diagnose tubereuze sclerose complex gesteld wordt, worden geconfronteerd met een onzekere toekomst, waarbij er een hoog risico is op de ontwikkeling van epilepsie, een ontwikkelingsachterstand en gedragsproblemen. In deze bijdrage worden de prognose en de keuze van behandeling gedurende het ziekteverloop van kinderen met het tubereuze sclerose complex besproken.

\section{Casus \\ Een 30-jarige zwangere vrouw wordt verwezen naar de kinderneuroloog voor prenatale counseling. Bij een amenor- roeduur van 29 weken wordt met behulp van echografie bij de foetus een afwijking gevonden ter plaatse van de tricus- pidaalklep verdacht voor een cardiaal rhabdomyoom.}

Een cardiaal rhabdomyoom is een van de hoofdkenmerken van de aandoening tubereuze sclerose complex
(TSC). Bij 80-90\% van de foetussen bij wie een cardiaal rhabdomyoom wordt gevonden, wordt later de diagnose TSC bevestigd. De kans op TSC is afhankelijk van grootte en aantal cardiale rhabdomyomen. De diagnose kan bevestigd worden met DNA-onderzoek, door een vlokkentest of een vruchtwaterpunctie te verrichten, of door aantonen van cerebrale afwijkingen met een prenatale MRI-scan. Bij deze zwangere werd een prenatale MRIscan verricht bij 35 weken amenorroeduur. De MRI van de foetus toonde aanwijzingen voor subependymale laesies waarmee de diagnose TSC werd bevestigd.

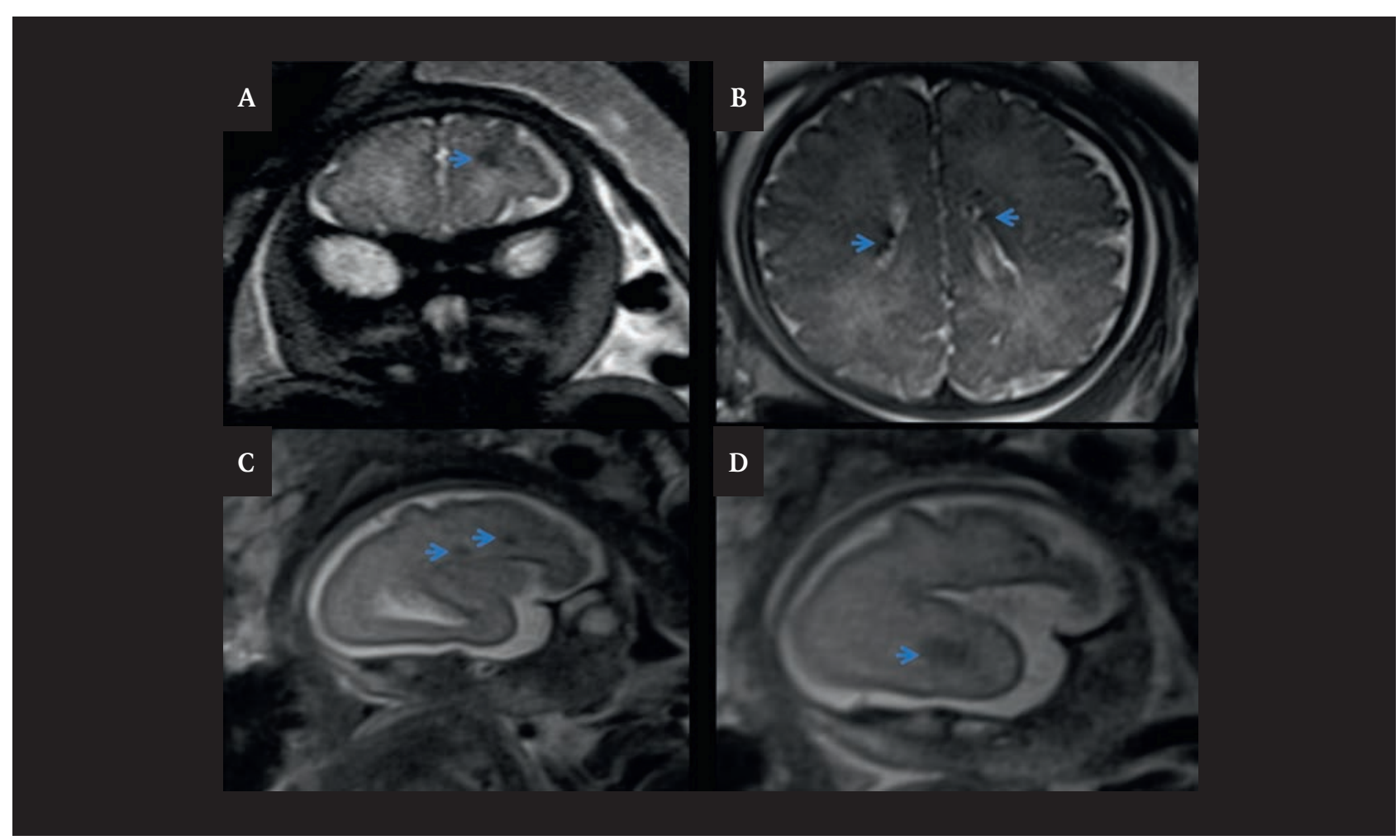

Figuur I foetale MRI met de volgende TSC-gerelateerde afwijkingen: subcorticale laesies verdacht voor tubers of dysplasie (A en D), subependymale laesies verdacht voor subependymale noduli ( $\mathrm{B}$ en $\mathrm{C}$ ). 


\section{Prognose}

De klinische manifestaties kunnen bij kinderen met TSC enorm variëren. Tot voor kort was er weinig bekend over de neurologische prognose van kinderen bij wie prenataal de diagnose TSC werd gesteld, mede doordat er steeds vaker gekozen wordt voor beëindiging van de zwangerschap, als een hoge verdenking op TSC is vastgesteld voorafgaand aan een zwangerschapstermijn van 24 weken.

Hulshof et al. (202I) verrichtte een retrospectieve multicentrum studie waarin onderzocht werd wat de relatie is tussen foetale MRI-afwijkingen en voorkomen van epilepsie en ontwikkeling op de leeftijd van twee jaar. Foetale MRI's werden gescoord om een zogenoemde cerebrale laesie somscore (exclusief subependymale laesies) te bepalen (range 0-20). In het onderzoek werden de foetale MRI's van 4I kinderen geanalyseerd. Een foetale MRI werd verricht bij een mediane zwangerschapsduur van 33 weken. De gemiddelde laesie somscore was viereneenhalf. Op de leeftijd van twee jaar had $58 \%$ van de kinderen epilepsie, bij $22 \%$ was deze moeilijk behandelbaar, en had respec-

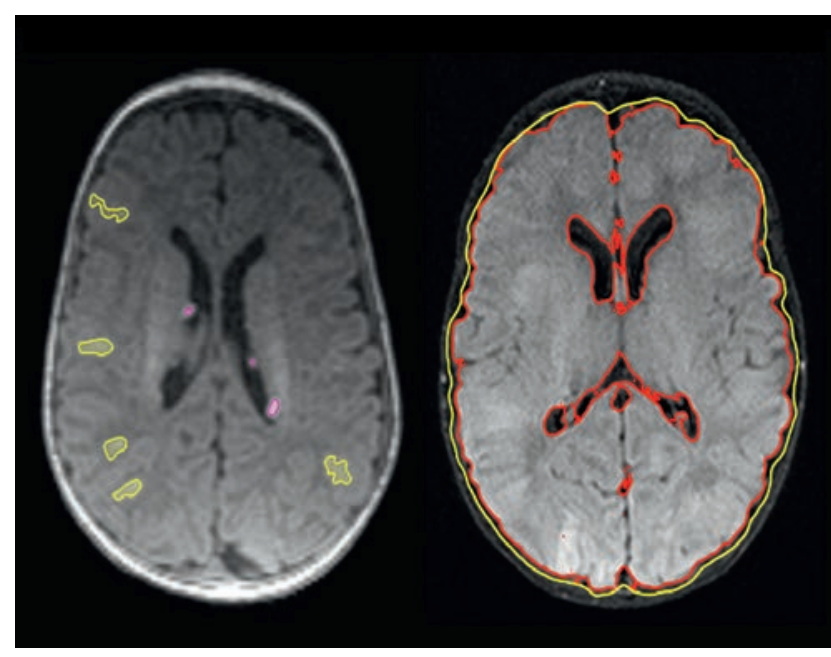

Figuur 2 Postnatale FLAIR MRI bij zuigeling van drie maanden waarin in geel tuber segmentatie is weergegeven (links) Op het rechter beeld een voorbeeld van de totale brein segmentatie warmee de ratio tuber/brein volume werd bepaald.

tievelijk $38 \%$, $81 \%$ en $50 \%$ een achterstand in cognitieve, taal of motorische ontwikkeling. Een verhoogd risico op een autismespectrumstoornis (gedefinieerd als een ADOSscore van tien of hoger) werd gevonden bij $20 \%$ van de kinderen. De foetale MRI-laesie somscore was gerelateerd aan zowel de cognitieve en motorische ontwikkelingsindex, als het risico op autisme, maar was niet gerelateerd aan het voorkomen van (refractaire) epilepsie of aan de debuutleeftijd van epilepsie.

Met dit onderzoek werd aangetoond dat de foetale MRIlaesie somscore een belangrijke rol kan spelen bij prenatale counseling.
Bij een groot aantal kinderen met TSC zal geen foetale MRI beschikbaar zijn. Hulshof et al. (202I) verrichtte een prospectieve multicentrum studie (als onderdeel van de zogenoemde Europese EPISTOP studie) waarin de MRIkarakteristieken bij zuigelingen met TSC jonger dan zes maanden gerelateerd werden aan epilepsie-karakteristieken en ontwikkeling op de leeftijd van twee jaar. Deze studie toonde dat aanwezigheid van tubers (62 van de 77 kinderen) en een hogere ratio tuber/brein volume geassocieerd is met het optreden van klinische aanvallen op de leeftijd van twee jaar. Een hogere ratio tuber/brein volume is op deze leeftijd bovendien geassocieerd met een lagere cognitieve en motorische ontwikkelingsindex, onafhankelijk van voorkomen van epilepsie en het genmutatie type (Hulshof et al., 202I). Naast MRI-karakteristieken is het type TSC genmutatie een belangrijke voorspeller voor de ontwikkeling van epilepsie en het verloop hiervan.

Pathogene veranderingen in het TSC2 gen zijn geassocieerd met ernstiger neurologische symptomen en meer MRI-afwijkingen (Ogórek et al., 2020).

\section{Timing van behandeling}

We weten dat vigabatrine bij jonge kinderen met epilepsie in het kader van TSC verreweg het meest effectieve medicijn is. Gezien het zeer hoge risico op epilepsie werd in 2014 de EPISTOP-studie gestart, waarin het effect van preventieve behandeling met vigabatrine, dat wil zeggen behandeling bij aanwezigheid van epileptiforme EEGafwijkingen voorafgaand aan het ontstaan van klinische aanvallen, werd vergeleken met standaard behandeling, dat wil zeggen start vigabatrine op het moment van het optreden van klinische aanvallen. Deze studie bij 94 zuigelingen met TSC, toonde dat kinderen die preventief behandeld werden met vigabatrine op latere leeftijd klinische aanvallen kregen en minder vaak een moeilijk behandelbare epilepsie hadden op de leeftijd van twee jaar (Kotulska et al., 202I). Het wordt daarom nu aanbevolen, door een Europees panel van experts, om kinderen, bij wie de diagnose TSC bekend is, voordat er klinische aanvallen worden gezien, maandelijks te vervolgen met klinisch- en EEG-onderzoek en vigabatrine te starten zodra het EEG epileptiforme activiteit vertoont.

\section{Behandeladviezen}

Bij veel kinderen zal de diagnose TSC pas gesteld worden na presentatie met klinische aanvallen. Uit studies naar het natuurlijk verloop van deze ziekte blijkt dat $70 \%$ van de pasgeborenen met TSC epileptische aanvallen hebben voor de tweede verjaardag. Zuigelingen presenteren zich meestal met focale aanvallen of met epileptische spasmen. Verschillende aanvalstypen kunnen ook gelijktijdig of na elkaar voorkomen. Een vroeg debuut van epileptische aanvallen is een sterke voorspeller voor vertraging van de 
ontwikkeling (Overwater et al., 20I7). Snelle adequate behandeling is noodzakelijk. In een Europese consensus bijeenkomst werden aangepaste aanbevelingen voor epilepsie behandeling geformuleerd (Curatolo et al., 2018a). Vigabatrine wordt aanbevolen als eerste keus medicament voor zowel focale aanvallen als epileptische spasmen bij kinderen met TSC onder de leeftijd van twee jaar. Effectiviteit van vigabatrine is met name beschreven bij infantiele spasmen en leidt tot aanvalscontrole bij 90\% van de patiënten. Indien vigabatrine niet effectief is bij epileptische spasmen dan is prednison of ACTH-therapie de tweede keuze voor behandeling van zuigelingen. Veel kinderen met TSC zijn niet langdurig aanvalsvrij. Ook op latere kinderleeftijd of in de adolescentie is vigabatrine een effectief anti-epilepticum. Uit een retrospectieve studie onder 49 kinderen en volwassenen met TSC bleek $25 \%$ aanvalsvrij te worden of een aanvalsreductie te hebben van $>90 \%$ en $6 \%$ had een aanvalsreductie van 50 tot $90 \%$ na toevoeging van vigabatrine (Friedman et al., 2013).

Bij 7I kinderen met TSC en epilepsie werd effectiviteit van behandeling op lange termijn onderzocht. Hoewel $77 \%$ van de kinderen aanvalsvrij werd met één of twee antiepileptica, duurde dat slechts bij 38\% langer dan 24 maanden. Ongeveer de helft van de laatste groep kreeg alsnog later een terugval. De kans op langdurige remissie is dus niet groot (Overwater et al., 2015).

\section{Bij alle patiënten met TSC met moeilijk behandelbare} epilepsie dient al in een vroeg stadium prechirurgische evaluatie overwogen te worden (Specchio et al., 202I). Echter, bij TSC is in het algemeen sprake van multiple wijdverspreide tubers en dit maakt het vaak lastig een epileptogene zone te identificeren. Soms is er een te uitgebreid epileptisch netwerk, maar bij een relevante groep kan met behulp van aanvullend prechirurgisch onderzoek, bestaande uit meerdaagse aanvalsregistratie, MRI-beeldvorming met $3 \mathrm{D}$-FLAIR en TI-opnames, hoge resolutie EEG of MEG, of SPECT, de epileptogene zone geïdentificeerd worden. Invasieve registratie, Stereo-EEG of GRIDregistratie, kan nodig zijn om de epileptogene zone af te grenzen of de relatie met eloquente cortex te bepalen. Aanvalsvrijheid wordt bereikt bij 55 tot $60 \%$ van de patiënten die geselecteerd worden voor epilepsiechirurgie. Ook bij multiple typen aanvallen kan met epilepsiechirurgie een belangrijke verbetering bereikt worden. Met succesvolle epilepsiechirurgie wordt niet alleen een betere aanvalscontrole bereikt, maar vaak ook een verbetering van de ontwikkeling en zeker een verbetering van kwaliteit van leven.

Effectiviteit van behandeling met mTOR-remmers zoals everolimus werd als eerste aangetoond voor groeiende hamartomen, te weten renale angiomyolipomen (AML) en subependymale giant cel astrocytomen (SEGA). Epileptogenese wordt ook verondersteld het gevolg te zijn van de dysregulatie van de zogenoemde mTOR-signaalroute (Proietti Onori et al., 202I). Na behandeling met everolimus voor een renaal AML en SEGA werd een vermindering van aanvalsfrequentie gerapporteerd. Deze observatie was mede aanleiding voor het verrichten van een internationale gerandomiseerde multicentrum-medicatie trial waarin het effect van toevoegen van everolimus vergeleken werd met de standaard anti-epileptische behandeling (French et al., 2016). Uit deze industriegeïnitieerde studie, waarin 366 patiënten met TSC werden gerandomiseerd naar placebo en behandeling met respectievelijk een lage en hoge dosering everolimus, blijkt dat everolimus een positief effect heeft op TSC-geassocieerde epileptische aanvallen met respectievelijke daling van mediane aanvalsfrequentie van $14.9 \%, 29.3 \%$ en $39.6 \%$. Aanvalsvrijheid werd bereikt bij respectievelijk 0.8\%, 5.I\% en $3.8 \%$ van de onderzoekspopulatie. Er werden veel bijwerkingen gemeld in de groep die behandeld werd met everolimus, maar dit leidde zelden tot stoppen van de medicatie. Een post-hoc analyse toonde dat vergelijkbare effectiviteit werd gezien in een subgroep van jonge kinderen en adolescenten. Ook werd in deze analyse aangetoond dat het effect voortduurde na een jaar behandeling en dat everolimus goed verdragen werd op jonge leeftijd (Curatolo et al., 20r8b). Er werd bovendien een retrospectieve observationele studie verricht om de veiligheid van behandeling met everolimus bij kinderen jonger dan twee jaar te evalueren (Krueger et al., 20I8). Epilepsie was de meest voorkomende indicatie voor behandeling met everolimus bij de 45 kinderen die in deze studie worden beschreven (45\%). De meeste bijwerkingen waren mild. Bij 20\% van de kinderen waren de bijwerkingen aanleiding om de behandeling te staken, maar levensbedreigende bijwerkingen ten gevolge van everolimus werden niet gerapporteerd. Vooralsnog is er onvoldoende bewijs dat behandeling met everolimus een gunstig effect heeft op de cognitie en het gedrag. Studies naar het effect van everolimus op autisme bij TSC lieten geen verbetering zien, hoewel diermodellen hier wel hoop op gaven (Krueger et al., 2017, Overwater et al., 2019). Het is echter waarschijnlijk dat timing van behandeling hierbij veel zal uitmaken. Een mogelijk gunstig effect van behandeling bij kinderen die op zeer jonge leeftijd met everolimus worden behandeld moet verder worden onderzocht.

In het Nederlands zorgpad voor kinderen met TSC en moeilijk behandelbare epilepsie heeft het ketogeen dieet een plek in de behandeling en wordt toegepast vanaf het falen van twee anti-epileptica, indien epilepsiechirurgie geen optie is. Ook kan een nervus vagus stimulator 
worden overwogen bij inacceptabele aanvalscontrole.

De laatste jaren komt in de spreekkamer steeds vaker de vraag naar voren of behandeling met cannabidiol effectief is. Eerder werd effectiviteit van epidyolex, een pure CBD olie, reeds aangetoond bij kinderen met Dravet syndroom en met het Lennox Gastaut syndroom. Recent werd effectiviteit aangetoond bij patiënten met TSC (Thiele et al., 202I). Deze RCT van 224 patiënten met TSC toonde dat behandeling van TSC-geassocieerde aanvallen met cannabidiol effectiever is dan een placebo, waarbij de aanvalsfrequentie daalde met $48,6 \%$ en $47,5 \%$ na behandeling met respectievelijk $25 \mathrm{mg} / \mathrm{kg} /$ dag en $50 \mathrm{mg} / \mathrm{kg} /$ dag CBD versus $26,5 \%$ daling bij patiënten die behandeld werden met een placebo. Bijwerkingen kwamen vooral voor bij de patiënten die behandeld werden met een hogere dosis CBD.

\section{Conclusie}

Epilepsie is een zeer veel voorkomend en bedreigend symptoom bij patiënten met TSC en een negatieve prognostische factor voor cognitie en gedrag. Klinische (MRI, EEG) en niet-klinische markers (moleculaire bevindingen, waaronder DNA-onderzoek) dragen in belangrijke mate bij aan herkennen van patiënten met een toegenomen risico op het vroege ontstaan van epilepsie. Adequate monitoring van patiënten met een hoog risico makkt vroegtijdige, zelfs pre-symptomatische, behandeling mogelijk. Vigabatrine is de eerste keuze bij kinderen onder de leeftijd van twee jaar. Bij moeilijk behandelbare epilepsie dient epilepsiechirurgie al vroeg overwogen te worden. Bij patiënten met moeilijk behandelbare epilepsie die niet in aanmerking komen voor epilepsiechirurgie behoren ketogeen dieet, mTOR-remmers, nervus vagus stimulatie en CBD, naast reguliere anti-epileptica, tot de behandelingsmogelijkheden.

\section{Referenties}

Curatolo P, Franz DN, Lawson JA, et al. (2018a).

Adjunctive everolimus for children and adolescents with treatment-refractory seizures associated with tuberous sclerosis complex: post-hoc analysis of the phase 3 EXIST-3 trial. Lancet Child Adolesc Health. 2(7):495-504

Curatolo P, Nabbout R, Lagae L, et al. (2018b) Management of epilepsy associated with tuberous sclerosis complex: Updated clinical recommendations. Eur J Paediatr Neurol. 20I8 Sep;22(5):738-748

French JA, Lawson JA, Yapici Z, et al. (2016) Adjunctive everolimus therapy for treatment-resistant focal-onset seizures associated with tuberous sclerosis (EXIST-3): a phase 3 , randomised, double-blind, placebo-controlled study. Lancet. 20I6, 29;388(I0056):2153-2163
Friedman D, Bogner M, Parker-Menzer K, et al. (2013) Vigabatrin for partial-onset seizure treatment in patients with tuberous sclerosis complex. Epilepsy Behav, 27(I):II8-20

Hulshof HM, Slot EMH, Lequin M, et al. (202I) EPISTOP consortium. Fetal Brain Magnetic Resonance Imaging Findings Predict Neurodevelopment in Children with Tuberous Sclerosis Complex. J Pediatr. 233:156-I62.

Kotulska K, Kwiatkowski DJ, Curatolo P, et al. (202I) EPISTOP Investigators. Prevention of Epilepsy in Infants with Tuberous Sclerosis Complex in the EPISTOP Trial. Ann Neurol. , 89(2):304-3I4

Krueger DA, Capal JK, Curatolo P, et al. (20I8) Research Group. Short-term safety of mTOR inhibitors in infants and very young children with tuberous sclerosis complex (TSC): Multicentre clinical experience. Eur J Paediatr Neurol. 22(6):I066-I073

Krueger DA, Sadhwani A, Byars AW, et al (2017).

Everolimus for treatment of tuberous sclerosis complexassociated neuropsychiatric disorders. Ann Clin Transl Neurol. Nov I2;4(I2):877-887.

Specchio N, Pepi C, de Palma L, et al (202I. Surgery for drug-resistant tuberous sclerosis complex-associated epilepsy: who, when, and what. Epileptic Disord.

Feb I;23(I):53-73.

Ogórek B, Hamieh L, Hulshof HM, et al., (2020) EPISTOP Consortium members, $\mathrm{TSC}_{2}$ pathogenic variants are predictive of severe clinical manifestations in TSC infants: results of the EPISTOP study. Genet Med. 22(9):I489-I497.

Overwater IE, Bindels-de Heus K, Rietman AB, et al. (2015) Epilepsy in children with tuberous sclerosis complex: Chance of remission and response to antiepileptic drugs. Epilepsia. 56(8):I239-45

Overwater IE, Verhaar BJ, Lingsma HF, et al (2017. Interdependence of clinical factors predicting cognition in children with tuberous sclerosis complex. J Neurol. Jan;264(I):I6I-I67.

Overwater IE, Rietman AB, Mous SE, et al. (2019)

ENCORE Expertise Centre for Neurodevelopmental Disorders. A randomized controlled trial with everolimus for IQ and autism in tuberous sclerosis complex. Neurology. 9;93(2):e200-e209.

Proietti Onori M, Koene LMC, Schäfer CB, et al (202I). RHEB/mTOR hyperactivity causes cortical malformations and epileptic seizures through increased axonal connectivity. PLoS Biol. 26;19(5):e300I279.

Thiele EA, Bebin EM, Bhathal H, et al. (202I) Add-on Cannabidiol Treatment for Drug-Resistant Seizures in Tuberous Sclerosis Complex: A Placebo-Controlled Randomized Clinical Trial.; GWPCARE6 Study Group. JAMA Neurol. I;78(3):285-292 